Simposio sobre endocrinología obstétrica y ginecológica.-Número 1 (*)

\title{
PRECOCIDAD SEXUAL EN LA MUJER
}

\author{
Doctor Edwin C. Hamblen (**)
}

(Traducción y resumen del doctor Gonzalo Echeverry P.)

Debe definirse con claridad en primer lugar lo que entendemos por precocidad sexual. Es un adelanto sexual definitivo en el que aparecen en la edad prepuberal todos los cambios sexuales, como desarrollo de los senos, aparición de vello pubiano y axi_ lar, repartición ginecoide de la grasa, menstruación, etc., al tiempo con un aumento definido en la edad ósea y dental, y aumento precoz de la estatura corporal.

No deben entenderse como casos de precocidad sexual aquellos en que se encuentran reacciones focales aisladas, como el hirsutismo esencial, la pubarquia idiopática (aparición de vello pubiano), la telarquía idiopática (desarrollo precoz de los senos), cuando no coexisten con el aumento de la edad dental y ósea.

Sentada esta definición, podemos clasificar la precocidad sexual en la mujer en tres tipos generales. No creemos necesaria una clasificación etiológica.

\section{TIPO I}

Es una precocidad isosexual y ginecoide, debida a la secreción prematura y autónoma de estrógenos por los ovarios, no estando éstos estimulados por una secreción hipofisaria de gonadotrofinas. Puede haber un hiperestrogenismo relativo o absoluto, y este

(*) Primer artículo de esta nueva sección, extractado de conferencias dictadas por el Profesor E. C. Hamblen en la Facultad de Medicina Javeriana en febrero de 1959 y publicado con su permiso.

(**) Profesor en Endocrinología de Duke University, Durhan U. S. A. 
tipo I no progresa nunca, hasta la madurez sexual completa. Lo usual es encontrar en este tipo de pacientes masas ováricas que pueden ser tumores sólidos productores de estrógenos, o más comúnmente, uno o varios quistes foliculares del ovario, con hipertecosis alrededor de la cavidad quística. Estos quistes foliculares pueden presentar a veces una hipertecosis de tipo casi adenomatoso, semejante a la que se encuentra en los ovarios del síndrome de Stein-Loewental o en pacientes con quistes virilizantes, y no se puede definir histológicamente si las células tecales hipertrofiadas serán productoras de andrógenos o de estrógenos.

Las pacientes del tipo I no llegan antes de tiempo a la madurez sexual completa, pero es frecuente observar que de todas maneras la pubertad completa se adelanta un poco en ellas, de acuerdo con el avance en su edad ósea y demás desarrollo somático.

En cualquier caso, este tipo de precocidad se trata por la cirugía ovárica conservadora, haciendo la extirpación del tumor funcionante o la cistectomía ovárica. Después de la operación, la joven detiene su progreso prematuro hacia la pubertad, y ésta se completa en su época normal, o a veces ligeramente anticipada. Esto no quiere decir que al extirpar el tumor o quiste ovárico que ocasiona la precocidad, todos los cambios aparecidos hasta el tiempo de la operación deban regresar. Estos permanecen en el estado en que estaban, pero la evolución a la pubertad precoz se detiene y no hay nuevo progreso hasta que el mecanismo normal de estímulo hipotalámico hacia la pituitaria, traiga la pubescencia normal y oportuna.

\section{TIPO II}

Es también isosexual y ginecoide, pero se debe a producción prematura de gonadotrofinas por la hipófisis con el consiguiente estímulo de los ovarios, y entonces la paciente progresará hasta la madurez sexual completa aún en edad muy temprana. Es el tipo que da los tan difundidos casos de madres-niñas.

Generalmente se trata de actividad hipofisiaria precoz de causa desconocida, pero hay casos en que la presencia de tumores vecinos del diencéfalo, pueden producir la irritación hipotalámica que traiga como consecuencia el desencadenamiento de la actividad hipofisaria. Lo mismo puede ocurrir en ciertos casos ce secuelas de formas encefalíticas de enfermedades por virus, o también en el llamado síndrome de Allbright o displasia fibrosa 
poliquística, en cuyo caso los quistes óseos producidos alrededor de la silla turca y en la vecindad del hipotálamo, pueden ocasionar la irritación hipotalámica que estimule a la pituitaria a entrar precozamente en funcionamiento. También se han observado casos del tipo II en pacientes con síndromes epilépticos.

En los estados iniciales, éstos dos tipos de precocidad pueden ser muy difíciles de diferenciar, pues ambos tienen la misma tencencia a mostrar producción precoz de estrógenos. Sólo cuando se puede identificar una masa ovárica y correlacionarla con la precocidad o cuando la paciente progresa tanto en su desarrollo que se tiene una prueba objetiva de que está llegando a la madurez sexual completa, se podrá hacer la diferenciación.

En el tipo II las gonadotrofinas urinarias se encuentran aumentadas, y en cambio en el tipo I, lo mismo que en las niñas normales, conservan sus niveles infantiles. En el tipo II, los estrógenos totales pueden exceder las cifras de la edad adulta, y en el tipo I, nunca llegarán a excederlos aunque estén aumentados. La prueba final del diagnóstico diferencial la dará la demostración de la existencia de ovulación, a la que sólo pueden llegar los casos del tipo II.

Solo en los casos en que se demuestre la existencia de un tumor de la región diencefálica o de secuelas tratables de una encefalitis, puede detenerse la evolución de las pacientes del tipo II. Los casos de actividad hipofisaria pura y precoz, son intratables, y los esfuerzos del médico, una vez establecido con precisión el diagnóstico, se dirigirán a dar soporte sicológico a estas pacientes, y muy especialmente a sus padres, quienes a veces se preocupan excesivamente por estas niñas y temen que puedan incurrir en indiscreciones sexuales. No hay razón para abrigar temores en este sentido, pues tomadas como grupo no manifiestan aparición precoz de la líbido. Hay que tratar de colocar estas niñas en un ambiente escolar adecuado a su desarrollo sexual, lo cual les evita el problema de estar asociadas con niñas de su misma edad cronológica, pero menos desarrollladas sexual y somáticamente. Afortunadamente estas niñas manifiestan un cierto avance en su desarrollo mental, lo cual facilita adaptarles sus estudios adecuadamente.

\section{TIPO III}

Es de muy fácil diagnóstico, pues es heterosexual y se debe al aumento de la producción de andrógenos, sea por producción 
autónoma de andrógenos debida a hiperplasia o tumor de la corteza suprarrenal, o a producción autónoma de andrógenos en los ovarios. Nunca he visto un tumor sólido virilizante de ovarios que produzca precocidad sexual, pero sí se encuentran ovarios poliquísticos o quistes foliculares con hipertecosis, y estas células tecales adematosas pueden ser productores de andrógenos, lo mismo que pueden serlo de estrógenos, sin que el aspecto microscópico indique su funcionalismo.

La característica clínica del tipo III es la precocidad sexual con virilización. No hay que olvidar que, especialmente en los estados iniciales de este tipo de precocidad sexual, hay que estar seguros de que evidentemente se trata de precocidad sexual y no de un estado de pseudoprecocidad, y por consiguiente, hacer las ảeterminaciones de edad ósea, dental, etc. Esta son pacientes francamente virilizadas aún a edades muy tiernas y presentan aesarrollo piloso, falo pronunciado, enronquecimiento de la voz, a.cné, etc.

Cuando se comprueba que la precocidad sexual virilizante se ciebe a tumores o a quistes foliculares ováricos, el tratamiento es naturalmente la extirpación de éstos.

Pero los casos más frecuentes son de etiología suprarrenal y entonces hay que distinguiur entre la hiperplasia adrenocortical y los tumores de la corteza. Esto se hace mediante el llamado test de supresión de cortisona, que consiste en hacer una dosificación cuidadosa de 17-cetosteroides urinarios y luégo administrar a la paciente cortisona o hidrocortisona. Si al hacer nueva titulación de 17-cestosteroides se encuentra que éstos han disminuído notablemente, se trata de una hiperplasia adrenocortical, y si permanecen en los mismos niveles, se tratará de tumor de la corteza suprarrenal.

En lo casos de tumor el tratamiento es obviamente quirúrgico. Los casos de hiperplasia adrenocortical se tratan con la administración a permanencia, de por vida, de cortisona o hidrocortisona. El fundamento de este tratamiento está en que, de acuerdo con la hipótesis de Wilkins y su grupo, se presume que ia corteza suprarrenal fabrica la cortisona como etapa final de un metabolismo hormonal que va pasando sucesivamente por progesterona, andrógenos, estrógenos, para llegar por fin a la cortisona. Ahora bien: en los casos de hiperplasia la lesión hace que este metabolismo no se complete, y en vez de producir las cantidades normales de cortisona, la corteza emplea toda su ac- 
tividad en la producción de andrógenos. Si a la paciente se le suministra terapéuticamente una dosis suficiente de cortisona, los niveles altos de ésta en la sangre obran como frenadores de la hipófisis en relación con la producción de ACTH, y disminuído o suprimido éste en la sangre, las suprarrenales no están ya bajo el estímulo de esta hormona adrenotropa y por consiguiente paralizan su función, cesando entonces la producción de andrógenos.

Hay que notar que hay signos de virilización que son completamente irreversibles, como son la hipertrofia del clítoris, la voz ronca, de manera que el tratamiento debe iniciarse lo más precozmente que se pueda. Las hipertrofias critoridianas marcadas se tratarán por cirugía.

Estas pacientes con precocidad sexual por hiperplasia, adrenocortical llegan a ser mujeres completamente normales tan pronto se suprime el exceso de andrógenos, tienen su pubertad ginecoide normal con aparición oportuna de menstruaciones, ciclos ovulatorios y fertilidad. 